\title{
ETHICAL ISSUES IN ATTEMPTS TO BAN REORIENTATION THERAPIES
}

\author{
MARK A. YARHOUSE \\ Regent University
}

The purpose of this article is to identify the ethical issues in efforts to ban reorientation therapies. The 3 primary arguments cited in the literature in favor of such a ban are discussed: (a) homosexuality is no longer considered a mental illness, (b) those who request change do so because of internalized homophobia, and (c) sexual orientation is immutable. The authors present 3 arguments in favor of providing reorientation and related services: (a) respect for the autonomy and self-determination of persons, $(b)$ respect for valuative frameworks, creeds, and religious values regarding the moral status of same-sex behavior, and $(c)$ service provision given the scientific evidence that efforts to change thoughts, behaviors, and feeling-based sexual orientation can be successful.

Professional discussions of same-sex attraction and behavior have shifted from whether homosexuality is a pathology to whether people who request reorientation therapy ${ }^{1}$ should receive these services. The question is, should clients

Mark A. Yarhouse, School of Psychology and Counseling, Regent University; Warren Throckmorton, Department of Psychology, Grove City College.

Correspondence regarding this article should be addressed to Mark A. Yarhouse, PsyD, School of Psychology and Counseling, Regent University, CRB 215, 1000 Regent University Drive, Virginia Beach, Virginia 23464. E-mail: markyar@ regent.edu

\author{
WARREN THROCKMORTON \\ Grove City College
}

who are distressed by their experiences of samesex attraction receive services to ameliorate their distress in a manner consistent with their beliefs and values? There are professionals who are working toward a ban on reorientation therapies, but what are the ethical issues in attempts to ban such therapies? At the outset of this article is a discussion of the three primary arguments cited in the literature in favor of such a ban: (a) homosexuality is no longer considered a mental illness, (b) those who request change do so because of internalized homophobia, and (c) sexual orientation is immutable. This is followed by a presentation of the three main arguments in favor of providing services to persons who report distress due to their experiences of same-sex attraction and/or behavior: (a) respect for the autonomy and self-determination of persons, (b) respect for valuative frameworks, creeds, and religious beliefs and values regarding the moral status of same-sex behavior, and (c) service provision in response to a clinical problem based on the available scientific research.

\section{Arguments in Favor of a Ban on Reorientation Therapy}

Homosexuality Is No Longer Designated as a Pathology

One of the most frequently cited arguments in favor of a ban on reorientation therapy is the vote by the full membership of the American Psychi-

\footnotetext{
${ }^{1}$ Although the focus of the present discussion is the value of reorientation therapy, there are in actuality a variety of approaches for patients who report distress due to their experiences of same-sex attraction, including chastity- or celibacybased approaches and sexual identity management, in which clients make conscious choices about both sexual behavior and social identity (Yarhouse \& Burkett, 2000). These other approaches do not of necessity attempt to change orientation.
} 
atric Association in 1974 to accept the recommendation of its board to remove homosexuality as a psychopathology from the subsequent edition of the Diagnostic and Statistical Manual of Mental Disorders (3rd ed. [DSM-III]; American Psychiatric Association, 1980). This is an intuitively appealing argument that is aptly summarized by the phrase "no sickness, no cure." In other words, treatments are provided for diseases, illnesses, or pathologies, and because homosexuality is no longer considered an intrinsically pathological condition, treatment should not be provided for it. It is often argued that the fact that treatments are offered at all indicates a pathology-based view of homosexuality. Some professionals who provide or defend the right to provide reorientation therapies have promoted a pathology model (Socarides, 1978), whereas others have suggested that homosexuality is a developmental abnormality rather than a psychopathology (Harvey, 1989). Still others appear to make no comment on the status of homosexuality other than to say that some people report distress due to their experiences of same-sex attraction and seek change (Lundy \& Rekers, 1995).

Does the very existence of reorientation therapies convey a pathology-based bias against homosexuality, and, if so, does this justify a ban on them? According to Bieschke, McClanahan, Tozer, Grzegorek, and Park (2000), "inherent in conversion therapy is the premise that same-sex orientations are pathological, an arrest in normal development, or (less stigmatizing but still homophobic and harmful in nature) not as well accommodated in society as a heterosexual orientation" (p. 313). This is an important consideration to members of the gay community. However, there is great diversity among reorientation therapies and related programs. Reorientation programs can convey the message that same-sex attraction is or signals an illness or pathology. It does not follow, however, that because some programs convey this message all programs convey this message, nor does it follow that the very existence of such programs means that homosexuality is a pathology. Not all reorientation programs take a disease- or pathology-focused approach to homosexuality (Throckmorton, 1998). What is particularly unsettling about the comment by Bieschke et al. is the implication that any approach to therapy other than an explicitly gay integrating approach conveys homophobia and is harmful.
Such an approach would leave the clinician with no other option than to provide therapy to integrate experiences of same-sex attraction into a gay, lesbian, or bisexual identity.

The related ethical question is this: What is a sufficient basis on which to provide treatment? Are a client's conflicts, wishes, and values a sufficient basis on which to provide services? Are services currently only provided for diseases, illnesses, or pathologies? The short answer to this question is no. Services are provided for nondisease states. Consider the case of abortion. Although abortion is an intervention to terminate a pregnancy, it hardly follows that pregnancy is a disease state or illness (McConaghy, 1993). Cosmetic surgery is another medical intervention conducted ethically as an elective procedure. Clearly, intervention can be ethically conducted for nondisease states involving rational voluntary choice.

It is ironic that the argument that homosexuality is no longer a pathology should be introduced into these discussions, as those who attempt to ban reorientation therapies run the risk of reverting to a pathology-based view of homosexuals themselves: "To regard homosexuals who wish to adopt a heterosexual life-style as not capable of informed choice, and therefore to deny them treatment to help them fulfill their wish, seems a return to the concept that homosexuals are severely maladjusted" (McConaghy, 1993, p. 137). Banning mental health services may imply that those requesting assistance are incompetent to make such a judgment.

The longer answer to the question of whether services should be provided for a nondisease state is that professional medical ethics has historically recognized the difference between disease states and clinical problems, a term Engelhardt (1996) recommended as an alternative term because of controversies surrounding what constitutes disease states: "Such a term would more accurately indicate the ways in which clusters of value judgments make conditions stand out as problems to be treated" and would "contribute to the long history of disputes regarding the nature of diseases" (p. 205).

Homosexuality per se is not classified as a disease state or illness. However, the distress and negative emotions that can accompany individuals who experience same-sex attraction and behavior as incompatible with personal or religious 
values are mental health concerns, and the fourth edition of the DSM (DSM-IV; American Psychiatric Association, 1994) acknowledges this. In fact, the $D S M-I V$ presumes that some clients will seek services related to their distress over sexual orientation or behavior (see DSM-IV Section 302.9 Sexual Disorder Not Otherwise Specified, where "a sexual disturbance" related to "persistent and marked distress about sexual orientation" is cited, p. 538; see also Section V313.82 Identity Problem, where it states "the focus of clinical attention is uncertainty about multiple issues relating to identity such as ... sexual orientation and behavior, moral values, and group loyalties," p. 685). The "no sickness, no cure" argument oversimplifies a potentially complex presenting concern that falls within the purview of the mental health profession. One possible response to "sexual disorder not otherwise specified" is to support a client's wish to reorient or confirm one orientation over another.

\section{Clients Are Motivated to Seek Treatment Because of Internalized Homophobia}

A second argument cited in favor of a ban on reorientation therapies is the belief that clients are motivated to pursue treatment because of internalized homophobia. The argument here is that people choose to treat their experiences of samesex attraction because they have internalized socioreligious prejudice against homosexuality. That people may cite religious or personal values as motivation to change is irrelevant; according to this argument, these values are derived from cultural and religious communities that promote stereotypes and prejudice against homosexuals. Homophobia used in this manner is so inclusive as to refer to any normative judgment that treats same-sex attraction or behavior as less desirable than heterosexuality. Thus, a religious view that prefers heterosexuality over same-sex orientation is homophobic by definition.

A corollary to this argument is that those who provide reorientation therapies are themselves guilty of prejudice. It is argued that clinicians collude with the internalized homophobia of their clients by agreeing to provide services to change sexual orientation. For example, Bieschke et al. (2000) argued that clinicians "who offer or even consider conversion therapy for their clients are ignoring the sociopolitical context that perpetu- ates both external and internal homophobia. Their values and belief systems are imparted to clients in detrimental ways" (p. 313).

The ethical issues assumed by this argument are whether mental health professionals respect diversity (organized conceptually by sexual orientation) and whether a willingness to provide change services constitutes harm through collusion with societal messages of prejudice against homosexuality. The main concern about defining the former as an ethical issue is that it incorporates only regard for one kind of diversity - that is, diversity organized around sexual orientation. There is seemingly no mention of or regard for diversity by religion or creed, in particular, beliefs and values about the moral status of samesex behavior and a broader normative vision for human sexuality.

Concerning the ethical issue of whether clinicians collude with societal messages of prejudice against homosexuality, it is important to consider the best way to discuss and explore a client's presenting concern. It is certainly conceivable that a client would have a strong negative reaction to same-sex feelings and that a clinician could collude with that because of his or her own strong negative reaction to same-sex attraction or behavior. But the concern here seems so broad as to condemn any alternative to a therapy that has as its goal the integration of same-sex attraction into a gay, lesbian, or bisexual identity. This leaves no latitude for clinicians to actually respect diversity insofar as differences include personal creed or religious beliefs as expressed within a diverse client population in an even more diverse and pluralistic society.

The charge of internalized homophobia is often leveled against clients who request change and clinicians who provide reorientation therapy. However, homophobia is a poorly defined construct at this time (O'Donohue \& Caselles, 1993). It appears to apply to any evaluation of same-sex attraction or behavior that is not decidedly gay affirmative. Of course, such an understanding is hardly consistent with a phobia in any meaningful sense of the word. Yet clinicians would not want to deny that internalized homophobia is plausible construct. Again, some clients may enter therapy because of an intense, irrational fear of same-sex attraction. Others, however, may rationally evaluate the moral status of same-sex be- 
havior and deem such behavior immoral ${ }^{2}$ or incompatible with other aspects of their worldview.

Concerning the charge that societal coercion brings clients into treatment, it is important to remember that although voluntary consent to treatment can be threatened by coercion from members of a treatment team (through threats to withdraw services, etc.), this same level of concern is not given to family members or a spouse, let alone to society as a whole (Grisso \& Appelbaum, 1998). The claim that all clients who seek treatment for same-sex attraction do so because of societal coercion not only lacks empirical support but stands outside of what is generally accepted in definitions of coercion. Indeed, this is an empirical question in every case; until a clinician conducts a thorough interview, he or she may not speculate what level and type of influence, if any, has been exerted on a client.

The reverse scenario is a greater ethical concern: Failure by the clinician to provide services or an appropriate referral to the client who is informed and competent and who voluntarily seeks services may be coercive. For example, Tozer and McClanahan (1999) stated that if "the therapist continues to refuse to provide conversion therapy, and the client continues to insist that he or she desires reorientation, the possibility of termination emerges. ... If the client remains steadfast in her or his desire to reorient to heterosexuality ... termination becomes a very real possibility" (pp. 738-739). The threat to withdraw services without referral because the client disagrees with integrating his or her same-sex feelings into a gay, lesbian, or bisexual identity may be coercive.

\section{Immutability of Sexual Orientation}

A third argument offered in favor of a ban on reorientation therapies is the claim that sexual orientation is immutable. This charge is often made alongside the claim that change programs do not work and that "success" stories are really stories of bisexuals who are responding to heteroerotic inclinations that were already present (Haldeman, 1994). Concerning whether reorientation therapies are successful, Tozer and McClanahan (1999) stated that "there is no empirical evidence to show that conversion therapy is effective in reorienting a lesbian, gay, or bisexual person to heterosexuality" (p. 722). With respect to bisexual "success" stories, Haldeman (1994) reviewed the research by Masters and Johnson (1979) and noted that only 9 of the 54 subjects self-identified as Kinsey 5 or 6, whereas the majority of subjects were apparently bisexual (the other 45 subjects ranged from 2 to 4 on the Kinsey scale): "It is likely that, rather than converting or reverting homosexual people to heterosexuality, this program enhances heterosexual responsiveness in people with already established heteroerotic sexual maps" (p. 223).

A recent corollary to the argument that change programs do not work is the charge that change programs may be harmful to participants. Haldeman (1994) raised this point after reviewing selected reorientation programs and religion-based ministries: "The research question, 'What is being accomplished by conversion treatments?' may well be replaced by, 'What harm has been done in the name of sexual reorientation?' At present, no data are extant" (p. 225).

The ethical issue related to whether reorientation programs work is that of scientific responsibility, and the logic appears to be as follows: Mental health professionals work from a scientific basis, and if (a) sexual orientation is immutable, (b) there is no empirical evidence in support of change, and (c) the change programs are shown empirically to be harmful to participants, then the programs should be banned as unethical. The problem with this conclusion is that every point is highly suspect.

The first two concerns-immutability and the effectiveness of treatment-can be addressed together. Experts in human sexuality do not agree

\footnotetext{
${ }^{2}$ It is important to remember that science cannot determine whether same-sex behavior is moral or immoral. Although empirical findings can contribute to a patient's understanding of the consequences of his or her behaviors, empirical findings cannot make a determination as to the moral status of a behavior. An additional concern is that some members of society are decidedly intolerant of those who hold strong moral commitments. As Engelhardt (1996) observed,

some have the strong moral conviction that strong moral convictions should not be had. Belief, commitment, and firm moral convictions are regarded as divisive at best and evocative of violence at worst. The world, they firmly believe, would be better off if there were less belief and moral conviction.... Such individuals tend to be intolerant of those who would merely tolerate (condemn but use no violence against those they condemn) instead of accepting the diversity of moral convictions that mark our condition. Ironically, such partisans of the value of moral diversity can be as intolerant as many of the religious communities they will not tolerate because of their strong moral convictions. (p. 77)
} 
on whether orientation is immutable; in fact, they do not agree as to what sexual orientation is. It is unclear whether sexual orientation is a universal, stable reality (an essentialist claim) or whether the categories of gay, straight, and bisexual are linguistic constructs fashioned by Western society to describe sexual preferences (a constructionist claim; see Throckmorton, 2000). There appear to be significant differences among those who experience same-sex attraction, including important differences between gay, lesbian, and bisexual persons. According to Gonsoriek, Sell, and Weinrich (1995), research is limited concerning change of sexual orientation. They noted, "Perhaps the most dramatic limitation of current conceptualizations is change over time. There is essentially no research on the longitudinal stability of sexual orientation over the adult life span" (p. 46).

More germane to the question of immutability is the empirical evidence in support of change. Only one report of change needs to be cited to refute the claim of absolute immutability, and nearly all of the early studies (1950s-1980s) that have been published-though they are methodologically less sophisticated than might be desired-report success for some percentage of persons studied. It should also be noted that poor methodology does not disprove success. More recent survey research clearly indicates by selfreport and therapist- or analyst-report that people say they experience change (e.g., MacIntosh, 1994; National Association for Research and Therapy of Homosexuality, 1997; Nicolosi, Byrd, \& Potts, 2000; Schaeffer, Hyde, Kroencke, McCormick, \& Nottebaum, 2000; Schaeffer, Nottebaum, Smith, Dech, \& Krawczyk, 1999; for a review, see Jones \& Yarhouse, 2000; Throckmorton, 2000).

The third concern is whether reorientation programs are harmful to participants. In discussions of ethical and professional issues in working with lesbian, gay, and bisexual clients, it is not uncommon for discussants to clamor to be the first to say, "Do no harm" (Drescher, 2001). This is an important principle, but it is often brought in as a trump card, implying that any other position advocates practices that are inherently harmful. We urge the reader to be cautious when this principle is raised in this way. The reality is that most stakeholders in these discussions want what is best for their clients. Not only do they want to avoid harm, they actually want to help those who seek their professional services. But the appeal to the Hippocratic oath is meant to suggest that reorientation or alternative therapies are inherently harmful. Yet the scientific research does not bear that out (e.g., Schaeffer et al., 1999, 2000). In fact, the appeal to the principle of "do no harm" raises more questions than it answers: Is it harmful to refuse services to people who request them because of a moral valuative framework that is in conflict with the present emphasis on gay identity integration? As we mentioned above, refusal to provide such services, discontinuation of services, or failure to provide an appropriate referral may be coercive.

To return to the original question of whether reorientation therapies are intrinsically harmful, Haldeman (1994) admitted at the time of his review that there were "no data" on the possible harm to participants, yet he referred to anecdotal accounts of harm, saying that "subjects who have undergone failed attempts at conversion therapy often report increased guilt, anxiety, and low selfesteem" (p. 225). The problem with anecdotal reports is that they carry no weight in scientific discourse. If researchers and theorists insist on rejecting anecdotal reports of successful change and positive benefits derived from reorientation therapies, then they must be consistent in rejecting anecdotal reports of harm. Scientists must be consistent in their decision to accept or reject anecdotal accounts of either success or harm from reorientation therapies.

With respect to empirical research, a study currently underway by Shidlo and Schroeder (1999, 2000) suggests that some participants (though not all) in reorientation therapy report harm, whereas some report positive benefits from participating in such therapy. This is a study of persons who had participated at one time in reorientation therapy or religion-based change programs and must be interpreted with caution because of the convenience nature of the sample. (The research was originally titled "Homophobic Therapies: Documenting the Damage" and is currently titled "Changing Sexual Orientation: Does Counseling Work?") In other studies (also of convenience samples), "feeling-based change of orientation" was positively associated with positive mental health at the time of the initial interview and at 1-year follow up (Schaeffer et al., 1999, 2000). Another survey from the Schaeffer research team (Nottebaum, Schaeffer, Rood, \& Leffler, 2000) compared people who were accepting of a gay or 
lesbian identity with those involved in a religionbased "ex-gay" program and found that both groups reported good mental health on measures of emotional well-being, with those who were accepting of a gay or lesbian identity having higher scores on those measures.

According to the empirical evidence to date, the objective of sexual reorientation has not been demonstrated to be intrinsically harmful. As was mentioned above, some clients may pursue change because of religious beliefs and values. Yet even the most devout religious clients may not experience change of orientation. And there may be an inherent conflict between biological drives (related to sexual attraction and object preference) and religious beliefs. Some may argue that this is an exceptional and unnecessary conflict; if the person were to just change his or her belief about the morality of same-sex behavior, the conflict would cease to exist. Yet some Christians, for example, respond to same-sex attractions and behaviors in much the same way they respond to other behaviors that fall outside of their understanding of a Christian sexual ethic. Consider the following quote, in which the authors discussed the possibility that people may not experience change following reorientation therapy and how that relates to a broader Christian sexual ethic:

As a "worst case" scenario let us suppose that change from homosexual preferences or experiences of same-sex attraction by human effort is found to be impossible. Such a finding would not necessarily change fundamental Christian teaching at all, in that God's standard for homosexual persons would continue to be the same as that for all persons. That standard is chastity in heterosexual marriage or celibacy outside of marriage. It may be that the church can no more guarantee healing to homosexuals than it can guarantee marriage to disconsolate single heterosexuals. There are many more single Christian heterosexuals "doomed" to sexual abstinence by the church's "narrow" sexual morality than there are homosexual persons similarly constrained. (Jones \& Yarhouse, 2000, p. 150)

Given the potential tension between sexual desires and religious values, it is important not to minimize the experiences of those who make the emotional and financial commitment to such therapy and, for whatever reason, choose to discontinue treatment. They may choose to discontinue treatment because of a change in their beliefs and values, negative experiences associated with their change efforts, financial considerations, or some other reason. The empirical data suggest that some people who have failed in treatment report experiencing anxiety, poor selfesteem, and depression (e.g., Shidlo \& Schroeder, 2001), and there are anecdotal accounts of other negative experiences (e.g., Haldeman, 1994). Clinicians can anticipate helping clients grieve losses associated with what they held out as a definition of success in treatment as well as losses they may face if they experience rejection from key sources of social support. Of course, specific clinical issues vary from case to case. For example, a religious client may struggle more with negative emotions toward God, religious leaders, or his or her religion in general. Others may struggle more with familial, ethnic, or societal views on human sexuality. Clinicians should identify those losses and look for ways to help the client establish or maintain meaningful social supports and practice specific coping activities, as one would when facing other significant losses.

In this context, side effects are a concern in most intervention programs and may or may not become an ethical concern, depending on how severe or enduring those side effects are and whether they are the experience of the vast majority of participants. In a discussion of how consequences of treatment play a role in informed consent, Grisso and Appelbaum (1998) discussed high benefit/low risk treatment, low benefit/high risk treatment, and low to moderate benefit/low to moderate risk treatment. Even if reorientation therapy were to fall in the most questionable of categories-low benefit/high risk (which it does not on the basis of the scientific evidence), then professionals would be interested in specifying the content of informed consent to treatment, not creating policies to ban reorientation therapy.

The main arguments cited in attempts to ban reorientation therapy are not compelling. They do not stand up to scientific scrutiny or logic, nor do they appear consistent with medical precedent and ethical practice. We turn now to the arguments in support of freedom to offer reorientation and related therapies.

\section{Arguments in Support of the "Right to Choose" Reorientation Therapies}

\section{Freedom and Self-Determination of Clients}

One of the most frequently cited arguments in support of a client's right to choose change therapy is the freedom and self-determination of the client: "Psychologists presume that people are 
autonomous, self-determining agents, particularly with respect to their ability to make decisions concerning their work in therapy" (Yarhouse, 1998, p. 250). This argument is grounded in ethical and legal history in which the shift from simple or implied consent to informed consent had an impact on the right to decline treatment and to choose among treatment modalities (Grisso \& Appelbaum, 1998). The historical shift occurred as "the courts focused on clients' right to make autonomous decisions, suggesting the importance of being able to select desired options, as well as to reject disfavored ones" (Grisso \& Appelbaum, 1998, p. 6).

The client's right to choose treatments that may or may not work has a long history in medicine. Further, there is a recognized tension in ethics between promoting well-being and respecting autonomy. Clients may choose that which puts them at risk for distress. What has arisen from this ethic is not a string of bans on interventions but a desire to maximize what clients need to know to give informed consent. This typically means that they receive information that the average client would deem relevant to his or her treatment decision and that a voluntary choice is made by a person who is competent to make such a choice (Grisso \& Appelbaum, 1998).

To facilitate informed consent in a manner consistent with medical precedent and established practice, clinicians should stabilize a client's emotional state prior to agreeing to work toward specific treatment goals, such as change of sexual orientation (Lundy \& Rekers, 1995). In addition, clinicians should clarify the presenting concern to understand what the client is really wanting from therapy, what motivates him or her to pursue specific goals, and how he or she will define "success" in treatment. It is also appropriate to review research on professional and paraprofessional or religion-based change programs as well as limitations to the existing research (see Throckmorton, 2000; Yarhouse, 1998).

\section{Respect for Diversity}

A second argument in favor of a client's right to choose change therapies is that the choice demonstrates regard for diversity. This is an often-overlooked consideration in these discussions. What is most often emphasized is the concern for diversity as defined by sexual orientation. This is an important aspect of diversity.
However, an equally important aspect of diversity has to do with one's creed or religious and personal valuative framework. To respect values that are different than one's own is to demonstrate regard for diversity (Yarhouse \& Burkett, 2000). To respect only the beliefs and values of those with whom one already agrees says nothing of one's capacity to respect diversity.

The ethical issue is whether clinicians fail to respect diversity as defined by creed, religion, or personal values in a diverse and pluralistic society. Mental health professionals face the difficult task of balancing respect for multiple expressions of diversity (e.g., sexual orientation, religion, and creed) in an attempt to provide services in an increasingly pluralistic society.

It is important to discuss exceptions to this respect for diversity. It is conceivable that a client may request services that are by some consensus inappropriate, and he or she may do so because of personal values. However, there is no consensus about the issue of homosexuality. Some clients choose to organize their identity around their religious beliefs no matter what sexual feelings they may experience. Clinicians are bound by ethics to respect varying world views. Respect for this choice of identity at least involves providing a tactful referral.

\section{Scientific Support for Change of Some Kind for Some Persons}

The third argument in support of the existence of change therapies is the scientific evidence of their helpfulness for some persons. Studies conducted during the 1950s-1980s included behavioral interventions (e.g., Freeman \& Meyer, 1975; Schwartz \& Masters, 1984), aversion treatments (e.g., MacCulloch \& Feldman, 1967; McConaghy, 1970), psychoanalysis (e.g., Hadfield, 1958; Hatterer, 1970), and group therapies from a variety of theoretical orientations (e.g., Birk, 1974; Munzer, 1965; Pittman \& DeYoung, 1971; Truax \& Tourney, 1971). Reported rates of positive outcomes are about $30 \%$, with many reports of still others experiencing progress in treatment. It is important to note that positive outcomes have been defined differently in different studies (e.g., decreased same-sex fantasy or behavior, increased opposite-sex fantasy or behavior, marriage). More recent survey research is generally consistent with the extant data, including MacIntosh's (1994) survey of 1,215 analysts who re- 
ported working with homosexual clients, of whom $276(23 \%)$ were said to have experienced a positive outcome. The survey published by the National Association for Research and Therapy of Homosexuality (1997) reported similar shifts following change efforts. ${ }^{3}$ The study by Spitzer (2001) also suggests that some people may experience change and that even those who were not as far along as they would have liked still believed that therapy was worthwhile and valuable given their values and vision of quality of life $\mathrm{e}^{4}$ (see also Schaeffer et al., 1999, 2000).

Critics are right to point out that many studies cited to support the effectiveness of professional change therapies and religion-based ministries suffer from poor methodologies, including small sample sizes, lack of clear definitions and consistency in measures of change or success, and use of therapist report and self-report of change. However, poor methodologies do not disprove success; what is needed are prospective, longitudinal studies of those entering such change programs and greater consistency as to what constitutes "success."

Also, as noted above, some clients do appear to report harm from involvement in reorientation therapy, whereas others do not. However, it seems clear that sexual orientation is not immutable in an absolute sense and that some persons who are involved in reorientation therapy or religion-based change programs report successful change of at least "feeling-based sexual orientation," whereas others report even more comprehensive changes (Robinson, 1998).

An additional consideration is the legal concern that attempts to ban reorientation therapy amount to "unreasonable restraint of free trade," a concern raised by the American Psychological Association's legal consultant when a proposal to ban such therapies was introduced to the Council of Representatives a few years ago (Zuriff, 1997, p. 305). According to Zuriff's account, the basis for any such action would need to be harm to clients who underwent such therapy, and this would need to be established through research. Ideally, research would be prospective and representative of those who pursue change.

Respect for the autonomy and self-determination of clients, regard for diversity, and the existing body of scientific research all favor the viability of reorientation therapies and paraprofessional or religion-based ministries. This is not meant to diminish the experiences of those in the gay community who see such programs as highly political, but it is a call for fairness, professionalism, and ethical practice on behalf of a diverse client population. Writing from a gay-affirmative perspective, Haldeman (2000) readily acknowledged the problems with the sociopolitical and religious contexts within which reorientation therapies are offered. He was concerned that the existence of such programs runs the risk of sending the wrong message about homosexuality. However, Haldeman also recognized that in a diverse and pluralistic society, there is a need to respect the rights of those who make choices that he and others would not make. His more balanced view offers professionals a way to respect all persons, a concern that should be foremost in the minds of those on both sides of the debate:

For some, it is easier, and less emotionally disruptive, to contemplate changing sexual orientation than to disengage from a religious way of life that is seen as completely central to the individual's sense of self and purpose. However we may view this choice, or the psychological underpinnings thereof, do we have the right to deny such an individual treatment that may help him to adapt in the way he has decided is right for him? I would say that we do not. This is why the mental health organizations have adopted advisory policies about conversion therapy that ... do not ... ban the

\footnotetext{
${ }^{3}$ Specifically, the results were that before the change treatment, $37 \%$ of respondents were exclusively homosexual, $31 \%$ were almost entirely homosexual, $22 \%$ were more homosexual than heterosexual, and the remaining $9 \%$ fell into the other categories of the Kinsey scale. Following their change experience, $15 \%$ reported being exclusively heterosexual, $18 \%$ were almost entirely heterosexual, $20 \%$ were more heterosexual than homosexual, $11 \%$ were equally homosexual and heterosexual, $23 \%$ were more homosexual than heterosexual, $8 \%$ were almost entirely homosexual, and $5 \%$ were exclusively homosexual.

${ }^{4}$ Spitzer (2001) studied a convenience sample of 200 persons who reported experiencing change of orientation. On the basis of his strictest criteria (no homosexual orientation), Spitzer reported that $10 \%$ of men and $40 \%$ of women reported the lowest scores on indicators of same-sex attraction, daydreams, lust, yearning for intimacy, masturbatory fantasies, thoughts, and so on following what they viewed as a successful change effort. Sixty-six percent of men and $44 \%$ of women reported good heterosexual functioning 1 year following what they identified as their successful change attempt (good heterosexual functioning included current heterosexual relationship, emotional satisfaction with partner rated a 7 or higher on a 1-10 scale, heterosexual sex at least a few times a month, physical satisfaction from sex rated at least 7 on a 1-10 scale, and never or rarely having homosexual thoughts during heterosexual sex).
} 
practice of conversion therapy outright out of concern for the individual whose personal spiritual or religious diversity may supersede his concerns about sexual orientation. (p. 3)

This more balanced approach provides a way to respect diversity as defined by sexual orientation and diversity as defined by religion or creed.

It is important to consider the best ways to respond to clients who report distress due to their experiences of same-sex attraction and/or behavior and request change. It may be helpful to strive to maintain a kind of therapeutic neutrality so clinicians are not attached to any one treatment outcome. A related concern is that therapists not provide services in a way that is manipulative insofar as they are telling the client what they "should" do or attempting to surreptitiously influence decision making. At a practical level, this could be evidenced in failure to discuss alternatives among approaches to treatment, including alternatives to reorientation therapy.

\section{Conclusion}

Several important ethical issues emerge from any discussion of reorientation therapy and attempts to ban such approaches. This article reviewed the three primary arguments cited in the literature in favor of such a ban and highlights the scientific, logical, and ethical problems inherent to each. This discussion was followed by a presentation of three arguments in favor of providing services to persons who report distress due to their experiences of same-sex attraction and/or behavior: (a) respect for the autonomy and selfdetermination of persons, (b) respect for valuative frameworks, creeds, and religious beliefs and values regarding the moral status of same-sex behavior, and (c) service provision in response to a stated need in light of the scientific evidence that efforts to change thoughts, behaviors, and feeling-based sexual orientation can be successful for some persons. It is important to clarify how clinicians can proceed in a way that is scientifically and professionally responsible, ethical, and respectful of all persons in a diverse and pluralistic society.

\section{References}

American Psychiatric Association. (1980). Diagnostic and statistical manual of mental disorders (3rd ed.). Washington, DC: Author.

American Psychiatric Association. (1994). Diagnostic and statistical manual of mental disorders (4th ed.). Washington, DC: Author.
Bieschke, K. J., McClanahan, M., Tozer, E., GrzegoreK, J. L., \& PARK, J. (2000). Programmatic research on the treatment of lesbian, gay, and bisexual clients. In R. M. Perez, K. A. DeBord, \& K. J. Bieschke (Eds.), Handbook of counseling and psychotherapy with lesbian, gay, and bisexual clients (pp. 309-335). Washington, DC: American Psychological Association.

BIRK, L. (1974). Group psychotherapy for men who are homosexual. Journal of Sex and Marital Therapy, 1, 29-52.

Drescher, J. (2001, May). Ethical issues surrounding attempts to change sexual orientation. In P. A. Bialer (Chair), Clinical issues and ethical concerns regarding attempts to change sexual orientation: An update. Paper presented at the annual meeting of the American Psychiatric Association, New Orleans, LA.

ENGELHARDT, H. T., JR. (1996). The foundations of bioethics (2nd ed.). New York: Oxford University Press.

Freeman, W., \& Meyer, R. G. (1975). A behavioral alteration of sexual preferences in the human male. Behavior Therapy, 6, 206-212.

GonsorieK, J. C., Sell, R. L., \& Weinrich, J. D. (1995). Definition and measurement of sexual orientation. Suicide and Life Threatening Behavior, 25 (Suppl.), 40-51.

Grisso, T., \& ApPElbaum, P. S. (1998). Assessing competence to consent to treatment. New York: Oxford University Press.

HAdFIELD, J. A. (1958). The cure of homosexuality. British Medical Journal, 1, 1323-1326.

Haldeman, D. C. (1994). The practice and ethics of sexual orientation conversion therapy. Journal of Consulting and Clinical Psychology, 62, 221-227.

Haldeman, D. C. (2000, August). Gay rights, client rights: The implications for sexual orientation conversion therapy. In M. A. Yarhouse (Chair), Gays, ex-gays, ex-ex-gays: Examining key religious, ethical, and diversity issues. Symposium conducted at the 108th Annual Convention of the American Psychological Association, Washington, DC.

HaRVEY, J. F. (1989). The homosexual person: New thinking in pastoral care. San Francisco: Ignatius.

HATTERER, L. (1970). Changing heterosexuality in the male: Treatment for men troubled by homosexuality. New York: McGraw-Hill.

Jones, S. L., \& Yarhouse, M. A. (2000). Homosexuality: The use of scientific research in the church's moral debate. Downers Grove, IL: InterVarsity Press.

Lundy, M. S., \& ReKers, G. A. (1995). Homosexuality in adolescence: Interventions and ethical considerations. In $\mathrm{G}$. A. Rekers (Ed.), Handbook of child and adolescent sexual problems (pp. 341-380). New York: Lexington Books.

MacCulloch, M. J., \& Feldman, M. P. (1967). Aversion therapy in management of 43 homosexuals. British Medical Journal, 2, 594-597.

MacIntosh, H. (1994). Attitudes and experiences of psychoanalysts. Journal of the American Psychoanalytic Association, 42, 1183-1207.

Masters, W. H., \& Johnson, V. E. (1979). Homosexuality in perspective. Boston: Little, Brown.

McConaghy, N. (1970). Subjective and penile plethysmograph responses to aversion therapy for homosexuality: A follow-up study. British Journal of Psychiatry, 117, 555-560.

McConaghy, N. (1993). Sexual behavior: Problems and management. New York: Plenum.

MunZER, J. (1965). Treatment of the homosexual in group 
psychotherapy. Topical Problems of Psychotherapy, 5, 164-169.

National Association for Research and Therapy of Homosexuality. (1997). A survey of sexual orientation change. Encino, CA: Author.

Nicolosi, J., BYRD, A. D., \& PotTs, R. W. (2000). Beliefs and practices of therapists who practice sexual reorientation psychotherapy. Psychological Reports, 86, 689-702.

Nottebaum, L. J., Schaeffer, K. W., Rood, J., \& LefFler, D. (2000). Sexual orientation: A comparison study. Manuscript submitted for publication.

O'Donohue, W., \& Caselles, C. E. (1993). Homophobia: Conceptual, definitional, and value issues. Journal of Psychopathology and Behavioral Assessment, 15(3), 177-195.

Pittman, F., \& DeYoung, C. (1971). The treatment of homosexuals in heterogeneous groups. International Journal of Group Psychotherapy, 21, 62-73.

Robinson, J. W. (1998). Understanding the meaning of change for married Latter-Day Saint men with histories of homosexual activity. Unpublished doctoral dissertation, Brigham Young University.

Schaeffer, K. W., Hyde, R. A., Kroencke, T., McCormick, B., \& Nottebaum, L. (2000). Religiously-motivated sexual orientation change. Journal of Psychology and Christianity, 19(1), 61-70.

Schaeffer, K. W., Nottebaum, L., Smith, P., Dech, K., \& KRAWCZYK, J. (1999). Religiously-motivated sexual orientation change: A follow-up study. Journal of Psychology and Theology, 27, 329-337.

SchwartZ, M. F., \& Masters, W. H. (1984). The Masters and Johnson treatment program for dissatisfied homosexual men. American Journal of Psychiatry, 141, 173-181.

SHIDLO, A., \& SCHROEDER, M. (1999, August). Changing sexual orientation: Empirical findings on conversion therapies. Paper presented at the 107th Annual Convention of the American Psychological Association, Boston.

Shidlo, A., \& Schroeder, M. (2000, August). National study of sexual orientation conversion: Empirical and conceptual issues. In M. A. Yarhouse (Chair), Gays, ex-gays, ex-exgays: Examining key religious, ethical, and diversity issues. Symposium conducted at the 108th Annual Convention of the American Psychological Association, Washington, DC.
Shidlo, A., \& Schroeder, M. (2001, May). Ethical issues in sexual orientation conversion therapies: An empirical study of consumers. In P. A. Bialer (Chair), Clinical issues and ethical concerns regarding attempts to change sexual orientation: An update. Paper presented at the annual meeting of the American Psychiatric Association, New Orleans, LA.

SoCARIDES, C. (1978). Homosexuality. New York: Jason Aronson.

Spitzer, R. L. (2001, May). Two hundred persons who claimed to have changed their sexual orientation. In P. A. Bialer (Chair), Clinical issues and ethical concerns regarding attempts to change sexual orientation: An update. $\mathrm{Pa}-$ per presented at the annual meeting of the American Psychiatric Association, New Orleans, LA.

THROCKMORTON, W. (1998). Efforts to modify sexual orientation: A review of outcome literature and ethical issues. Journal of Mental Health Counseling, 20, 283-304.

Throckmorton, W. (2000, August). Review of empirical findings concerning ex-gays. In M. A. Yarhouse (Chair), Gays, ex-gays, ex-ex-gays: Examining key religious, ethi$\mathrm{cal}$, and diversity issues. Symposium conducted at the 108th Annual Convention of the American Psychological Association, Washington, DC.

Tozer, E. E., \& McClanahan, M. K. (1999). Treating the purple menace: Ethical considerations of conversion therapy and affirmative alternatives. Counseling Psychologist, 27, 722-742.

TruaX, R. A., \& Tourney, G. (1971). Male homosexuals in group psychotherapy. Diseases of the Nervous System, 32, 707-711.

Yarhouse, M. A. (1998). When clients seek treatment for same-sex attraction: Ethical issues in the "right to choose" debate. Psychotherapy, 35, 248-259.

Yarhouse, M. A., \& Burkett, L. A. (2000, August). Respecting religious diversity. In M. A. Yarhouse (Chair), Gays, ex-gays, ex-ex-gays: Examining key religious, ethical, and diversity issues. Symposium conducted at the 108th Annual Convention of the American Psychological Association, Washington, DC.

ZurifF, G. E. (1997, April). Psychology's sexual disorientation. The World \& I, 12, 299-311. 